\title{
В.И. Кабрин
}

Томский государственный университет (Томск, Россия)

\section{Креативное лидерство в холодинамике коммуникативных миров самообновляющейся организации}

\author{
Рассмотрена коммуникативно-холистическая модель креативного \\ лидерства в университете в качестве универсального гармонизирующего \\ фактора его сочиально-психологического самообновления. Выделены \\ характеристики уровней эмерджентного, аттрактивного, фрактального и \\ символического лидерства, определяющего холархию коммуникативных миров \\ университета. Модель предлагается использовать как проект по гармонизации \\ отношений основных коммуникативных миров, в котором развиваются \\ оппонируюшие идеи и проекты. \\ Ключевые слова: креативный лидер; университет как самообновляющаяся \\ организация; коммуникативно-холистическая модель креативного лидерства. \\ Университет - это место, \\ где общество и государство \\ позволяют сознанию эпохи \\ развернуться в наивысшей форме. \\ К. Ясперс. Идея университета
}

\section{Введение}

Качество существования и динамика развития любой сочзиальной организации во многом определяются своеобразием взаимоотношений институциональных (официальных) и человеческих (неформальных) связей людей как сотрудников и как личностей. Если иерархическое административно-профессиональное функционирование организации документально регламентировано и регулируемо, то миры неофициальных человеческих отношений образуют спонтанно-креативную стихию. Она характеризуется социально-психологической самодостаточностью, но в силу своей спонтанной диффузности «неофициально» обволакивает и административнопрофессиональную деятельность организации, определяя общую морально-психологическую атмосферу и динамику ее эмоционально-психологического климата. Эта неформальная, сугубо человеческая жизнь организации влияет на многие характеристики ее эффективности, а в случае хронических конфликтов и негативного отношения к характеру ее функционирования может приводить и к опасным нарушениям, и к тупиковым ситуациям в ее жизни в целом. Это общеизвестный факт. 
Весь XX в. характеризуется развитием множества социальноэкономических, социокультурных и социально-психологических подходов и моделей решения этого многогранного комплекса проблем. При этом современные обобщающие проекты, особенно в духе «творческого холизма», представляются вполне перспективными (М. Джексон, А.М. Жалевич, Р. Акофф) [1-3]. Но остается все же нерешенной принципиальная проблема организационной экзистенции - проблема соразмерности, совместимости и синхронистичности институционально-административной и персонально-трансперсональной жизни такого человечно-бесчеловечного образования.

Однако в современную постиндустриальную, а вскоре и постинформационную эпоху «идея университета» может стать общей метафорой полноценной жизни любой организации. Университет как архетипическая идея всегда порождал перспективу единства образования, науки, творчества в коллективном межличностном самоосуществлении. В связи с этим Р. Акофф и Д. Гринберг отмечают, что «уже стало очевидным, что постиндустриальный образ жизни, безотносительно к охватывающей его культуpe, придает большое значение таким ее видам, как творчество, оригинальность, эстетическое удовлетворение, красота, понимание, любознательность, стройность мылиления, мудрость. Душа постиндустриального человека занята главным образом постоянной, внутренне побуждаемой борьбой за открытие новых тайн, создание новых образцов, завоевание новых просторов разума» [3. С. 77].

Основной гипотезой нашего проекта становится предположение, что универсальное «образование», в котором жизнь социальной организации и личности могут быть полноценно совместимы, - это коммуникативный мир как хронотоп иенностно-смысловых отношений. Именно в них реализуется творческий процесс, объединяющий предназначение, исполнение миссии и личности, и социума [4-6]. В контексте этой идеи нетрудно представить и личность не как подкожное существо, а как созвездие коммуникативных миров, к которым она причастна, включая ее собственный персональный мир, и организацию как созвездие и холархию коммуникативных миров, в которых очень по-разному задействован ее персонал.

\section{Модель творческой гармонизации субмиров коммуникативного мира университета}

Возможно, будет достаточно драматичной гармония мира университета в силу контактно-конфронтационных напряжений между его оппонирующими «субмирами». Однако из-за их взаимодействия и заинтересованности друг в друге такая их транскоммуникативная гармонизация приведет к плодотворной эмердженции социально-психологической и духовной атмосферы коммуникативного мира университета в целом и его субмиров в соответствии с его официальным и духовным предназначением. Университет в качестве многоуровневого коммуникативного мира самоорганизуется 
и саморазвивается в контексте единого духовно-ценностно-смыслового поля, определяющего достойную избирательность и активность коммуникативных отношений со средой $[4,5]$.

Поскольку аналогичными характеристиками обладают и персональные К-миры всех сотрудников, преподавателей и студентов, абитуриентов и выпускников, то существуют потенциальная и реальная их соизмеримость и совместимость, а значит, и возможность персональной идентификации с высшими и актуальныли ценностями университета. Это может естественным образом приводить к гармонизации и синхронистичности [7] разноуровневых транскоммуникаций и транскоммуникативных отношений. Такой духовно-психологический климат не может не сказываться на качестве жизни и творческой продуктивности. В этом контексте может быть решена сложнейшая экзистенциальная дилемма образования, сформулированная Р. Акоффом в 2009 г.: «Сегодня существуют два разных мира, употребляющих слово образование в противоположных смыслах. Один мир состоит из школ, колледжей и университетов, составляющих наш образовательный комплекс, в котором преобладает стандартизация. В этом мире мегаструктура индустриального тренинга стремится выпускать идентичные образцы продукции, называемой «люди, получившие образование для XXI века». Второй мир - мир информации, знаний и мудрости, в котором находится реальное население, в то время когда не отбывает заключение в школах. В этом мире обучение происходит как всегда, а преподавание состоит в передаче мудрости, среди прочего, добровольным слушателям» [3. С. 27].

Университет как многоуровневый коммуникативный мир образует динамичное изенностно-смысловое единство с его «предельньли элементами» - фракталами, которые сохраняют существенные свойства целого- персональных коммуникативных миров соучастников творческой жизни. Такой взгляд на университет позволяет рассматривать этот саморазвивающийся коммуникативный мир с позиций современных креативно-холистических моделей, учитывая при этом его первичную ценностносмысловую природу. «Творческий холизм» как новая метафорическая парадигма преодолевает на основе «теории сложности» (новой синергетики) ограничения традиционных функционально-механистических системных моделей социальных организаций [1].

Учитывая разнообразие социальных организаций в связи с ростом их избирательных внешних и внутренних связей, М. Джексон предлагает перейти от жестких наукообразных парадигм, характеризующихся взаимным отторжением и войнами, к метафорам, располагающим к креативной преемственности. Им предложены четыре основных взаимопреемственных принцииа холизма, возможность реализации которого в анализе жизни коммуникативного мира университета видится перспективной, особенно в контексте проблемы развития креативного лидерства.

Принщип эмерджентной сложности предполагает качественную трансформативность организации при выведении ее на предельную уда- 
ленность от центра равновесия. При этом в качестве диссипативной структуры (И. Пригожин) она становится чувствительной к «взмаху крыльев бабочки», но сохраняет свою ноэтическую ценностно-смысловую сущность, видимо, в качестве «странного аттрактора».

Принции аттрактивности предполагает поиск латентного центра или вектора притяжения, удерживающего внешне хаотические динамизмы (холодайны) в границ̧ах их общего аттрактора.

Принции фрактальности подразумевает самоподобие всех относительно артикулированных (оформленных) фрагментов разных уровней организации. Они не иерархически (опосредованно), а холархически (непосредственно) подобны и синхронистичны целому (особенно по смыслу).

Принцип архетипической символичности паттернов проявляет себя в наличии на разных уровнях организации устойчивых паттернов персонального воображения и поведения, слабо рефлексируемых, но энергетически и эйдетически хорошо ощутимых.

Предполагается, что потенциальная синхронистичность всех процессов жизни организации, названных здесь принципиальными, делает ее элегантной, эстетически (этически) привлекательной для сотрудников и стейкхолдеров даже в период «непостижимой» эмердженции. Типичные немеханистичные метафоры, отмечаемые М. Джексоном, - это организациия как организм со своими болезнями и способами их лечения; ncuxиamрическая больнища, где парадоксальным образом начальники лечат подчиненных, и наоборот. И если организация - это большой сумасшедший дом, то его подразделения (факультеты, кафедры и т.п.) похожи на «малые сумасшедшие домики», как и семьи. На «вечном карнавале» сотрудники и студенты разных уровней и курсов периодически «перелицовываются» (в том числе под видом магистерских программ и «стратегических академических единиц»), примеряя различные формальные и неформальные маски-роли на себя и друг на друга. Существуют, конечно, и метафоры «школы» с постоянным переучиванием компетенций и т.п.

Для дальнейшей интерпретации и проектирования креативного лидерства в неформальных структурах организации, определяющих ее не административный, а социально-психологический климат, предлагаем метафору университет как личность. Еще К. Ясперс в «Идее университета» писал: «Жизнь университета зависит от личности, а не от институции, каковая является лишь предпосылкой. Поэтому об институции следует судить по тому, может ли она привлечь лучших и создает ли благоприятные условия для их исследований, коммуникации и учебы... неизбежно возникает напряжение, которое до тех пор, пока живет идея университета, должно вести к преобразованиям» [8. С. 97].

Кроме официального статуса, университет обладает индивидуальносвоеобразным лицом со своей биографией, историей, культурой, витальностью, болезнями, развлечениями, трагедиями и праздниками. Но в отличие от предыдущих метафор главное в ней - это иченностно-смысловая одухотворенность и цуелеустремленность в контексте своего коммуникативно- 
го мира, т.е. мира персонифицируемых значимых коммуникативных отношений в своем внутреннем и внешнем жизненном хронотопе. Организация и личность в этой метафоре не только соразмерны, но и едины. Это единство наиболее рельефно проявляется не в официальном соуправлении, а в креативном распределенном лидерстве. Можно вообразить «вулканическую энергию» харизматического суперлидерства [9], pаспределяюшуюся по интуитивно важным аттрактивнылм направлениям (ветвящегося суператтрактора) организации.

«Распреде́ленная» идея исходного суперлидерства децентрируется и распределяется между инициативными, аттрактивными лидерами, одержимыми новыми векторами (аттракторами) полицентрического развития организации, во фрактально разнообразном и совместимом креативном ко-лидерстве проблемно-проектных групп. На этой основе мы можем перейти от классических альтернативных моделей к единой холархической модели преемственного полицентрического лидерства.

\section{Полицентрическая модель лидерства в эмерджентно развивающейся организации}

Полицентризм, возможно, одно из главных качеств холистического видения мира, что исходит из его ноэтического понимания. Один из ярких современных представителей такого понимания П.Т. Шарден выразил это весьма исчерпывающе: «Атомы - это центры универсума» [10. С. 225]. Возможность представить холистическую сложность жизни организации по аналогии с жизнью личности позволяет нам видеть феномен лидерства во всем разнообразии проявлений: холархически - от организации целого до персоналий; холодинамически - в каждой фазе активности. Универсален здесь концепт потенциализащии, разработанный нами применительно к анализу развития потенциала достижений личности. Он понимается как рост креативных возможностей личности в любых значимых ситуациях. Относительно группы, организации ее потенциализация будет означать рост инициатив креативного лидерства, сообразного конкретной специфике обстоятельств и целей, а потому - потенщиально эффективного.

Потенциализация креативности и потенциализация лидерства имеют общий глубинный корень - встречу с новым, неизвестнылм. «Креатив»в отличие от «Стереопата» открывается навстречу неизвестному и, чувствуя противоречие, принимает его с готовностью инициативно работать, контактировать с ним, т.е. «лидировать». Но в силу открытости риску он ориентирован и чувствителен также к отклику, «ответу» со стороны «неизвестного» (проблемы, незнакомца и т.п.), т.е. открыт синхронной обратной связи (СОС). Эти два фактора - чувствительность к принимаемым противоречиям (ЧП) и СОС - составляют условия маленького чуда настоящей встречи - позитивную стресс-транс-формаџию (СТФ) одного или обоих партнеров встречи как момент их творческой эмердженции, т.е. рождение нового транссмысла, имеющего новую перспективу воплощения [11]. 
Важно подчеркнуть, что в ситуации СОС партнеры одновременно являются «лидерами положения», но в разных аспектах, - а это креативная перспектива встречи. Как и встреча, креативное лидерство всегда возможно, но никогда не гарантировано. В этом сходство моментов творчества и лидерства. Очевидно, что это разные аспекты единого процесса встречи с неизвестным. Это происходит, когда образуется удивительная синхронистичность взаимной предрасположенности (готовности) партнеров и обстоятельств. Поэтому лидерство и администрирование (управление) оказываются часто несмешиваемыми процессами, которые, однако, можно сонастроить как взаимодополнительные. В этом, в частности, может заключаться основная миссия руководителя организации в качестве лидера.

\section{Транскоммуникативная холархия лидерства}

На основе четырехуровневой холархической модели организации выявляются креативные типы лидерства, которые соответствуют уровню и масштабу «ассимилируемых» ими противоречий и создают необходимую синтеграцию (напряженное единство) [1] коммуникативных процессов.

A. Эмерджентность организациии в цчелом. Организация в данной определенности живет во временной период между эмердженциями, а затем может преобразиться в простейшем случае в свою противоположность на всех уровнях.

Эмерджентный лидер, наделенный эмерджентной креативностью, будет чувствовать узел противоречий и время их освоения, а также время неизбежной эмердженции. В этом смысле он заложник в борьбе вечных высших и сиюминутных актуальных ценностей жизни организации. По отношению к другим он будет выглядеть харизматичным (если сможет стать убедительным) в принятии труднопредсказуемых решений, имеющих реальный риск не осуществиться, если в кризисе эмердженции система разрушится, «демонтируется». Столкновение «вечных» и «моментальных» цеенностей - стихия жизни этого уровня эмерджентного лидерства.

B. Аттрактивность векторно напряженных пересекающихся пространств организации. Любая организация имеет векторы напряжения разной степени осознанности между следующими «областями ментальности»:

- между «чувствами корней» (пониманием неизбежной принадлежности к...) и пониманием миссии как достойной перспективы;

- между чувствованием «почти безграничных резервов» и пониманием ограниченности актуальных ресурсов;

- между уважительным отношением к выстраданным уважаемым традициям и уверенностью в необходимости создания прорывных проектов, ломающих старые устои и задающих новое движение организации;

- между богатым «заповедником» еще не реализованных идей, «альтернативных проектов» и чувствительностью к принципиально нoвblм $\mathrm{bbl}$ зовам, «стучащимся» в двери организации. 
Аттрактивно-креативный лидер, по-видимому, должен быть и одержимым (по-своему выдающимся), чтобы объять одно из четырех основных противоречий жизни организации и сделать их, таким образом, синтегративными. Необходим высокий уровень аттрактивной креативности, которая предполагает выраженную предрасположенность к napaдоксальной кониептуализации, т.е. к синтезу несовместимого или противоположного. В каждой организации требуется поиск своих специфических аттракторов. Их может быть больше или меныше рассмотренных выше. Нам же представляется важным исследовать состояние именно данных биполярных аттракторов в качестве факторов «преемственного развития» университета (между эмердженциями).

С. Фрактальная динамика бесконечного информачионного разнообразия основных функционально-оперативных образований организации. Выделим важные «информационно-энергетические» коммуникативные центтры, которые находятся на векторах основных аттрактивных напряжений (см. пункт $B)$.

1. На аттрактивной «вертикали» - парадигме перспективы - синтегративно противостоят (при взаимопроникновении) друг другу:

- коммуникативный мир, поддерживающий понимание и переживание значимости представлений о корнях жизнеспособности и принадлежности (например, к культурно-исторической, научно-образовательной элите страны и т.п.);

- коммуникативный мир, в котором обсуждаются новые перспективы и проекты, обеспечивающие реализацию предназначения и миссии и определяющие будущее организации, ее смысл и качество жизни.

2. На аттрактивной «горизонтали» - парадигме существования организации - противостоят при взаимопроникновении друг другу:

- коммуникативный мир, где обсуждаются сложные проблемы выявления актуальных трудностей и расширения резервов организации по разным направлениям в связи с выраженной проблемой приоритетов;

- коммуникативный мир, в котором остро обсуждаются вопросы оптимального задействования наличных ресурсов в приоритетных направлениях выживания и развития организации.

3. На аттрактивной «диагонали» (глубинно-импрессивной) интегративно противостоят:

- коммуникативный мир, в котором активна перспектива углубленного обзора большого количества идей, замыслов, проектов, почти «заготовок», которым надо найти достойное применение;

- коммуникативный мир, где участники очень чувствительны к вызовам социума и понимают, что для соответствия этим вызовам нужны принципиально новые подходы, необходимо формулировать новые задачи и функциональные центры организации.

4. На аттрактивной «диагонали» - достойно-экспансивном векторе прогресса организации - совместно противостоят: 
- коммуникативный мир, где обсуждаются и поддерживаются лучшие традиции, прошедшие проверку временем, которые олицетворяют внутреннее самоуважение и достоинство организации;

- коммуникативный мир, объединяющий людей проницательных, мыслящих будущим, создающих неожиданные рискованные венчурные проекты и готовых активно отстаивать необходимость их приоритетной реализации для выхода на новый уровень эффективности и качества жизни организации.

Креативный лидер фрактального уровня - это, как правило, «лидер мнения», генератор впечатляющих идей, замыслов, проектов, изобретений. Фрактально-генеративный лидер может чувствовать себя властителем или вестником определенного информационного потока, к которому пробуждена его интуиция. Поэтому он не скупится на «задумки» и стимулирует пробуждение своей особой креативной самостоятельности у других участников группы, подразделения или просто у единомышленников. Сам он неутомимый автор комбинациий, композиций, конструкций, решений. Придать им изящную, эстетически правильную форму ему не по силам, так как он не дизайнер.

Сложная, во многом даже подвижническая миссия креативного лидера аттрактивного уровня $B$ заключается не только в том, чтобы найти общий язык с генеративнылми лидерами своего направления, но и в том, чтобы открыть объединяющую и впечатляющую обоих свежую идею.

D. Паттернально-символическая динамика энергетически насыщенных экспрессивно-дизайнерских оформлений и форм представления основных дел и событий организации. Потенциально организация для себя и для других может сверкнуть, блеснуть впечатляющим событием, фактом, достижением из любой точки ее многоуровневого и многогранного коммуникативного мира. В этом состоит реальный полицентризм организации. В предлагаемой здесь гипотетической схеме такой сияющий ореол организации отчетливо может возникать и обнаруживаться в связи с восемью полюсами ее аттрактивных направлений. Можно рассматривать такие искрящиеся презентации как своеобразное продолжение и дизайнерское эстетическое заострение представленных здесь коммуникативных миров как информационно-энергетических центров.

1. Ценностно-смысловая композиция миссии организации может быть воплощена в виде захватывающей и впечатляющей «Мистерии посвящения». При этом ритуал посвящения будет по закону импринтинга формировать глубинную корпоративную мотивацию неофита.

2. Эстетическая кристаллизачия «Мифа происхождения» (оживляемого в первом ритуале) может стать эмоционально-этической подпиткой многих сотрудников.

3. Эффектная удачная реализация ресурсов может содействовать эстетически привлекательному дизайнерскому оформлению «Репутации», содействующей внешнему представительству организации. 
4. Внимательная эффективная работа с резервами может продолжиться в оформлении элегантного почетного архива (подогреваемого «Репутацией»).

5. Бдительное проектирование принятия новых социальных заказов и вызовов времени может быть эффективно оформлено как проницательная чувствительность и мудрость в мониторинге грядущих вызовов.

6. На противоположенном полюсе аттрактора вышеназванная активность ведет к постоянному переосмыслению и оценке богатства того, что уже задумано. «Заповедник» сохранивиихся идей и проектов может вселять уверенность в принятии более сложных вызовов, если они будут оформлены более привлекательно.

7. Поддержание жизнеспособности достойных традиций может оформляться как золотой фонд корпоративной культуры, поддерживающий подобающее качество жизнедеятельности организации.

8. Качество и реализуемость прорывных проектов могут быть эстетически оформлены как «Авангард», символизирующий перспективу реального развития организации в целом.

По характеру последних задач уже можно представить исключительную важность уникальной одаренности, талантливости, архетипически персонифицированного авторства креативного символического лидера, хотя он работает над приданием эстетически привлекательной значимой формы результатам работы всего коллектива. Без таких романтических лидеров - мастеров символического дизайна - облик организации может оказаться скучноватым, малопривлекательным для стейкхолдеров. Однако надо иметь в виду и опыт организаций-«пустышек», «однодневок», начинающих свою деятельность с создания пышного, эффектного ореола, за которым еще или в принципе ничего нет. Пока не лопнет такой «мыльный пузырь», «организаторы» успеют отравить атмосферу и вызвать отвращение к подобным фейерверкам как к набившей оскомину рекламе. Но это лишь заостряет проблему и подчеркивает необходимость поиска настоящего дизайна для реальных достижений организации.

Мы также не считаем этот символико-дизайнерский представительский уровень жестко структурированным, т.е. выделенные по принципу обобщения и иррадиации восемь коммуникативных полей не привязаны к отдельному коммуникативному центру, от которого они могли бы быть производными. Но, видимо, они вбирают в себя символизм других центров, поэтому их локализация в предлагаемой ниже схеме условна и может быть как бы «плавающей».

Обобщая возможности анализа полицентрического креативного лидерства в организации, мы предлагаем его коммуникативно-холистическую модель. Она представлена в форме концентрических кругов, обозначающих уровни организации и соответствующие холистические типы креативного лидерства.

При этом аттрактивный уровень организации целесообразно отобразить в виде векторов, что делает модель в целом более экспрессивной. По- 
этому мы отказались об изображения всех возможных связей между всеми факторами модели (образующими полнылй граф) для сохранения рельефности и более существенной наглядности.

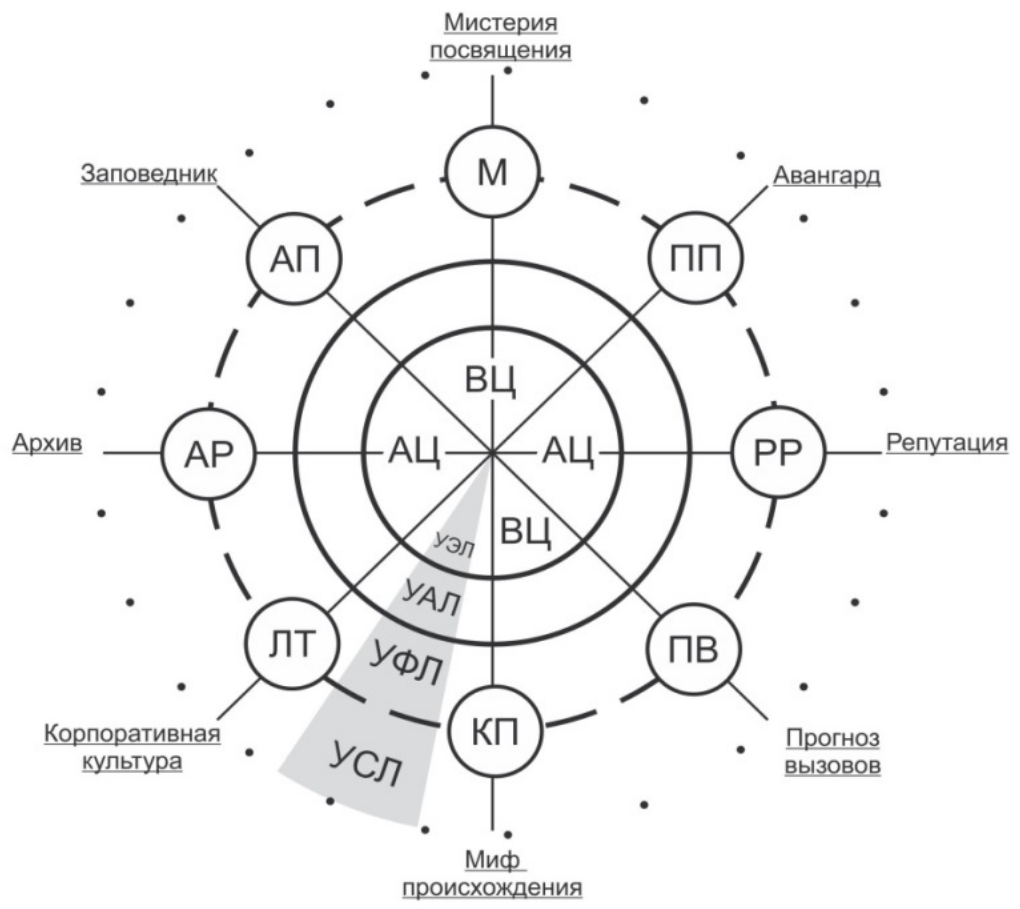

Принятые сокращения (приводятся в соответствии с оппонирующими аттрактивными полями): ВЦ - высшие ценности и АЦ - актуальные ценности; М - миссия университета и КП - корни выживания и принадлежность; $\mathbf{P P}$ - реализуемые ресурсы и $\mathbf{A P}$ - актуальные резервы; АП - альтернативные проекты и ПВ - принятые вызовы; ЛТ - лучшие традиции и ПП - прорывные проекты. Уровни: УЭЛ - уровень эмерджентного лидерства; УАЛ - уровень аттрактивного лидерства; УФЛ - уровень фрактального лидерства; УСЛ - уровень символического лидерства.

Рис. 1. Полицентрическое лидерство в коммуникативных мирах самообновляющейся организации

В самом начале мы высказали предположение, что в обществе будущего, возможно, сам университет как идея станет моделью создания самообновляющихся организаций, строящихся на принципах холистического полицентризма. Предложенная модель может стать основой исследовательских и экспериментальных программ. Все названные факторы могут быть превращены в схемы опросников, глубинных интервью и контентанализа релевантных проблеме текстов. Результаты исследования могут составить портрет университета в заданном ракурсе. На этой основе может быть создана экспериментальная программа работы координационных 
центров, дискуссионных групп согласно уровням модели, а также межгрупповых дискуссий по проработке проблемных связей между разными коммуникативными мирами университета. Кроме конкретных эффектов оптимизации коммуникаций, такая акция может придать новый мотивационный импульс в консолидации усилий для действенного самообновления. Это открывает перспективу сравнительного и прогностического исследования заинтересованных организаций не только университетского типа.

\section{Литература}

1. Джексон М.С. Системное мышление: творческий холизм для менеджеров / науч. ред. и пер. с англ. Ф.П. Тарасенко. Томск : Изд. Дом Том. гос. ун-та, 2016. 404 с.

2. Жалевич А. Мудрость лидера. М. : Эксмо, 2015. 640 с.

3. Акофф Р., Гринберг Д. Преобразование образования. Томск : Изд. Дом Том. гос. унта, 2009. $196 \mathrm{c}$.

4. Кабрин В.И. Коммуникативный мир и транскоммуникативный потенциал жизни личности : теория, методы, исследования. М. : Смысл, 2005. 248 с.

5. Кабрин В.И. Транскоммуникативные основания анализа ценностного мира человека // Ценностные основания психологической науки и психология ценностей. М. : Институт психологии РАН, 2008. С. 124-123.

6. Кабрин В.И. Концепция творческой коммуникации (из опыта психологических практик) // Сибирский психологический журнал. 2011. № 40. С. 152-164.

7. Юнг К. Синхрония: акаузальный объединяющий принцип : сборник статей. М. : ACT, 2010. $347 \mathrm{c}$.

8. Ясперс К. Идея университета. Минск : Белорус. гос. ун-т, 2006. 159 с.

9. Кабрин В.И. Креативное лидерство: транскультуральная перспектива // Сибирский психологический журнал. 2015. № 58. С. 121-136. DOI: 10.17223/17267080/58/9

10. Шарден Т.Д. Феномен человека. М. : АСТ, Астрель, Полиграфиздат, 2012. 381 с.

11. Кабрин В.И. Транскоммуникативная эмердженция человеческих отношений как открытие новых смысловых контекстов жизни // Психологические проблемы смысла жизни и акме : электронный сборник материалов XX симпозиума. М. : Психологический институт PAO, 2015. С. 66-69. URL: http://www.pirao.ru/images/labs/ gporl/\%D0\%A5\%D0\%A5-simpozium.pdf

Поступила в редакиию 17.12.2016 г.; принята 15.02.2017 г.

КАБРИН Валерий Иванович, доктор психологических наук, профессор кафедры психологии личности, научный руководитель Лаборатории психологических практик факультета психологии Томского государственного университета (Томск, Россия). E-mail: kabrin@list.ru

\section{CREATIVE LEADERSHIP IN HOLODYNAMICS OF THE COMMUNICATIVE WORLDS OF SELF-RENEWED ORGANIZATION}

Siberian journal of psychology, 2017, 63, 170-182. DOI: 10.17223/17267080/63/12

Kabrin Valeriy I., Tomsk State University (Tomsk, Russian Federation). E-mail: kabrin@list.ru

Keywords: creative leader; university as a self-renewed organization; communicative and holistic model of creative leadership.

The situation of qualitative changes and emergent changes in many spheres of society highlights the problem of the fundamental transformation of the leading socio-cultural and 
socio-economic organizations. One such organization, with an impressive history and future is a classical university. This article assumes that the transition into a post-industrial information and post-information society could bring to the forefront the idea of a university being a universal institution and a promising model for other organizations. In the context of this hypothesis we explore on the communicative and holistic model of a university as a research and a pilot project.

Holistic ideas by R. Ackoff and M. Jackson relate to the author's concepts of transcommunication and multi-level communication worlds. The concepts are incorporated in the project analysis of holarchies of successive creative leadership, defining axiological and psychological environment in a university.

The level of emergent complexity of the organization defines time and sharpens challenging contradictions between the actual and the highest values. An emergent leader with his charismatic wisdom to foresee coordinates and integrates social-psychological qualities.

The level of multi-vector attractiveness of an organization, where conceptual attractors hold in a single direction different oppositional ideas, requires the attractive leader with significant abilities of paradoxical conceptualization. Such leader is able to find a unifying and inspiring idea for oppositional concepts.

The level of a fractal variety of generated and implemented ideas by a number of groups requires a variety of fractal leaders as the generators of ideas. Such leader awakens the creative activity of other members of the group and tones the overall environment.

The level of archetypal symbolic design of ideas is present in any organization responsible for the high-quality presentation of the results. Such leader of the artistic and attractive decisions has a unique talent to create a unique image and glory of an organization.

Structural framework of the organization is formed by the attractive vectors on the poles of which a variety of fractal and generative leadership is formed.

In a classical university the dialogue of real communicative worlds occurs. The worlds represent: highest values; reinterpretation of the mission and fundamentals; effective implementation of the resources and actualization of the reserves; discussion of the alternative projects and new challenges; preservation of the best traditions; and guarantee of the success of new breakthrough projects.

The glory of the design leadership of an organization might look like: a work for reputation and memory; a mystery of dedication and a myth of origin; the forecasts of challenges and a reserve of ideas; the virtues of a corporate culture and the creative avant-garde. In accordance with the above mentioned aspects we are working on designing a research project and we are creating the discussion groups, which would harmonizing the psychological environment of an organization.

\section{References}

1. Jackson, M.S. (2016) Sistemnoe myshlenie: Tvorcheskiy kholizm dlya menedzherov [Systemic thinking: Creative holism for managers]. Translated from English by F.P. Tarasenko. Tomsk: Tomsk State University.

2. Zhalevich, A. (2015) Mudrost' lidera [Wisdom of the leader]. Moscow: Eksmo.

3. Akoff, R. \& Grinberg, D. (2009) Preobrazovanie obrazovaniya [Transformation of education]. Translated from English by F.P. Tarasenko. Tomsk: Tomsk State University.

4. Kabrin, V.I. (2005) Kommunikativnyy mir i transkommunikativnyy potentsial zhizni lichnosti: teoriya, metody, issledovaniya [Communicative world and transcommunicative potential of a person's life: theory, methods, research]. Moscow: Smysl.

5. Kabrin, V.I. (2008) Transkommunikativnye osnovaniya analiza tsennostnogo mira cheloveka [Transcommunicative bases of the analysis of the axiological world of people]. In: Znakov, V.V. \& Zalevskiy, G.V. (eds) Tsennostnye osnovaniya psikhologicheskoy nauki $i$ psikhologiya tsennostey [Axiological bases of psychology and the psychology of values]. Moscow: Institute of Psychology, Russian Academy of Sciences. pp. 124-123., 
6. Kabrin, V.I. (2011) Kontseptsiya tvorcheskoy kommunikatsii (iz opyta psikhologicheskikh praktik) [The concept of creative communication (from psychological practice)]. Sibirskiy psikhologicheskiy zhurnal - Siberian Journal of Psychology. 40. pp. 152-164.

7. Jung, K. (2010) Sinkhroniya: akauzal'nyy ob"edinyayushchiy printsip [Synchrony: an acausal unifying principle]. Translated from German. Moscow: AST.

8. Jaspers, K. (2006) Ideya universiteta [The idea of the university]. Minsk: BGU.

9. Kabrin, V.I. (2015) Creative Leadership: Transcultural Perspective. Sibirskiy psikhologicheskiy zhurnal. 58. pp. 121-136. (In Russian). DOI: 10.17223/17267080/58/9

10. Chardin, T.D. (2012) Fenomen cheloveka [The Phenomenon of Man]. Translated from French by N.A. Sadovsky. Moscow: AST, Astrel', Poligrafizdat.

11. Kabrin, V.I. (2015) Transkommunikativnaya emerdzhentsiya chelovecheskikh otnosheniy kak otkrytie novykh smyslovykh kontekstov zhizni [Transcommunicational emergence of human relations as the discovery of new semantic contexts of life]. In: Vayzer, G.A., Kiselnikova, N.V. \& Popova, T.A. (eds) Psikhologicheskie problemy smysla zhizni i acme [Psychological problems of the meaning of life and acme]. Moscow: Psychological Institute of the Russian Academy of Education. pp. 66-69. [Online] Available from: http://www.pirao.ru/images/labs/ gporl/\%D0\%A5\%D0\%A5-simpozium.pdf.

Received 17.12.2016; Accepted 15.02.2017 